ill defined right hypochondrial and epigastric discomfort was felt. However, these symptoms were sufficiently severe to demand cessation of therapy. They improved and subsequently disappeared soon after therapy with these drugs was suspended. So it appeared to us that abnormality of alanine transaminase was a good indication of hepatotoxicity in these patients.

These tests have now been adopted as routine in this clinic in all patients receiving therapy with rifampicin and isoniazid in any combination. It will be interesting to see whether patients showing abnormality of SGPT are also slow acetylators. This may be a good screening test for those who will be treated with this very effective combination and is to be investigated.-I am, etc.,

Chest Clinic,

Churchill Hospital,

C. O. ANAH

\section{Depressive Illness and Aggression in Belfast}

SIR,-I was most interested to read the paper by Dr. H. A. Lyons ( 5 February, p. 342) concerning depression and aggression in Ulster. However, I wonder what account has been taken of the effect of the disruption of general practitioner care on the referral of patients to hospital outpatients during the present troubles. It would seem to me that this might well have had an effect on the figures for the referral of depressive patients per se, but would be less likely to have affected the figures for suicide attempts. -I am, etc.,

Newcastle General Hospital.

J. R. ASHTON

Newcastle upon Tyne

\section{Bacteroides Infections}

SIR,-We read with interest the paper by Dr. Oonagh Tracy and her colleagues (29 January, p. 280) on "Lincomycins in the Treatment of Bacteroides Infections."

In their article they mention that they were unaware of any published clinical account of the use of this group of antibiotics in the treatment of such infections. At the Fifth International Congress of Chemotherapy held in Vienna in 1967 we described the case of a 55-year-old woman suffering from diverticulitis associated with bacteroides septicaemia, which responded satisfactorily to lincomycin.' The minimum inhibitory concentration of the organism for lincomycin was $0.25 \mu \mathrm{g} / \mathrm{ml}$. - We are, etc.

\section{A. M. GEDDES}

East Birmingham Hospital,

J. F. MUNRO

\section{Birmingham}

1 Geddes, A. M., Munro, J. F., Murdoch, J. McC., of the 5 th., and Burns, B. A., in Proceedings of the 5th International Congress of Chemo thor. 1, p. 361. Vienna, Wiener Medizinisch Akademie, 1967.

\section{Torsion of Testis}

SIR, - Your timely leader and the article by Di R. H. Chapman and Mr. A. J. Walton (15 January, p. 164) emphasize the problems of diagnosis of torsior of the testicle. My own approach to any patient referred with a diagnosis of epididymitis is to ask myself first if this could be either torsion or tumour. Torsion is common, is commonly overlooked, and is often misdiagnosed as epididymitis. The latter is the most frequent diagnosis in general practice, and in a small "epidemic" of torsions which I dealt with some years ago-some 35 cases in 2 months - the correct diagnosis was made only once by the general practitioner.

Having seen two patients referred as having appendicitis, who in fact had torsions, I was glad to see Mr. Thomas Moore's letter (5 February, p. 374). At first sight, the pain may be similar, but I find that it is of ten rather lower and more medial than is usual in appendicitis, and the signs of peritonitis are less marked than one would ex-

pect for the severity of the pain if it were caused by appendicitis.

As the congenital anatomical anomaly which makes torsion possible is in my experience always bilateral, I find it of value to examine the unaffected testicle. If the anomaly is present, the testicle can be turned easily through $180^{\circ}$ or more so that the lower pole is uppermost. The normal testicle tends to flip back at about $160^{\circ}$. This test, incidentally, is also of great value in cases of chronic or recurrent torsion or in those occasional individuals with longstanding testicular pain for which no cause is immediately apparent.

There is really only one disaster in exploration-namely, to explore a testicular tumour through a scrotal incision in mistake for a torsion. This, however, is another problem.-I am, etc.,

Department of Urology, Newcastle General Hospital,
New castle upon Tyne

D. M. ESSENHIGH

SIR,-I have read with interest the recent correspondence on this subject (5 February, p. 373) and would like if I may to make three further comments.

There is nothing new about manual reduction. About 16 years ago I reported case which I had successfully reduced and described how this should be attempted by the practitioner who first sees the case. This was the all-important point I made, as unless a fully-blown torsion is reduced within an hour or two of its onset it is probably a waste of time reducing it at all Long-term reviews have shown that most of those cases which were thought to have been successfully treated surgically ended up with atrophied testes.

My second point concerns diagnosis Torsion of the testicle is undoubtedly the commonest cause of pain and swelling in a young boy, but is by no means the only cause, as several of your correspondents have pointed out. Unfortunately so much publicity has recently been given to misdiagnosis of torsion that many young surgeons are exploring testes quite unnecessarily. I am afraid this has happened on several occasions in recent years on my own unit. That operation does no harm is no excuse for faulty diagnosis.

Finally, and most important of all, if one does explore a testis and if its viability is doubtful, for heaven's sake do not remove it! Even if one leaves a completely infarcted testis all that will happen is that it will atrophy. The slightest bit of healthy testi- cular tissue is probably better than nothing. One never knows what might happen to the other.-I am, etc.,

Ashford Hospital,

ROBIN BURKITT Ashford, Middx

1 Burkitt. R. British Medical fournal, 1956, 2, 345.

\section{Doctor-Patient Relationships}

SIR,-Dr. H. W. Ashworth's pessimismPersonal View (12 February, p. 437)astounds me. Here is a man who qualified when I did in 1944, who has lived through all the improvements affecting general practice in the last quarter of a century, who has the advantage moreover of working with good doctors in a university teaching practice, and who yet can say "popular opinion of the profession reaches a new low" and "In America the public hate the doctors while in this country the doctors hate the patients. It may not be long before our patients emulate their American cousins." My own view is almost diametrically opposed to his.

A more educated and literate public are certainly helping to dispel some of the mumbo-jumbo and black magic on which the profession has relied in the past to maintain its authority. This is surely a good thing because it helps to keep doctors alert and thinking. To explain the diagnosis, treatment, and prognosis of a serious medical condition to an educated patient, a doctor must really understand the condition himself. With better understanding of individual episodes of illness comes increasing wisdom, better medical care, and a b-tter doctor-patient relationship.

There are undoubtedly potential risks to this relationship in the modern trend towards group practice, and if the profession is not fully aware of these its public image could well deteriorate. The main danger is of doctors taking the easy way out and seeing any patients in the group who ask to see them instead of training all patients to attach themselves to one doctor only. Many patients do not mind which doctor they see. but doctors who have looked after their own patients consistently know that this is better for patients as well as doctors.

If these risks are borne in mind, however, the many advantages of group practice to the doctor such as adequate leisure, freedom from non-clinical work, and regular contact with colleagues for discussion will help to improve standards of medical care, and tension between the public and the professinn is likely to decrease.

All of us are biased by our experience and I personally have found that patients nowadays are generally more considerate in their demands than they were in the early years of the National Health Service. I don' think I am alone in this feeling.-I am, etc.

DENIS CRADDOCK

South Croydon

\section{Unfair to Baboons}

Sir.-The recent book $^{1}$ and newspaper arricles in the Sundnv Times (September 1971) hy Jane Goorall have made it quite clear that some primates are animals of intelligence with a social order and family sense. They abpear to nossess many emotions in common with Homo sapiens. How 